


\title{
LA EXPRESIÓN PAR A NADA Y SU EVOLUCIÓN EN EL ESPAÑOL ORAL. LA INFORMACIÓN DEL USO EN LOS DICCIONARIOS
}

\author{
Inmaculada Anaya Revuelta \\ Universidad de Vigo \\ ianaya@uvigo.es
}

\begin{abstract}
Resumen
Este trabajo analiza la evolución del uso de para nada desde su aparición con valor final hasta el momento actual en el que aumenta el uso como actitud de rechazo. Además de los tres diccionarios que sirven como punto de partida, el análisis se realiza sobre 388 casos correspondientes a tres períodos (1975-1985, 1992-2002 y 2006-2016) del Corpus de Referencia del Español Actual y del Corpus del Español del siglo XXI. En los diccionarios analizados se han revisado las marcas de uso, cuya información gramatical y lexicográfica nos parece insuficiente. El uso adecuado o no de para nada como rechazo absoluto depende, en buena medida, de factores pragmáticos que informan sobre el contexto, el nivel de lengua y la interacción entre los participantes.

Palabras clave: para nada, lengua oral, nivel coloquial, pragmática, marcas de uso.
\end{abstract}

Title: The expression para nada and its evolution in spoken Spanish. Information about its use in dictionaries

\begin{abstract}
This paper analyses the evolution of the use of the expression para nada ever since its appearance to convey purpose, up to the present time, to convey an attitude of rejection. Besides the three dictionaries, which served as the starting point for the research, the analysis covers 388 cases over three time periods (1975-1985, 1992-2002, and 20062016) taken from the Corpus de Referencia del Español Actual (Current Spanish Reference Corpus) and the Corpus del Español del siglo XXI (21 ${ }^{\text {st }}$ Century Spanish Corpus). The analysis of the usage labels in the dictionaries revealed insufficient grammatical and lexicographical information. The proper or improper use of para nada as total rejection largely depends on pragmatic factors that inform about the context, language level and interaction between the participants.
\end{abstract}

Keywords: para nada, spoken language, colloquial level, pragmatics, usage label. 


\section{INTRODUCCIÓN}

El estudio de la expresión para nada parte de una aclaración realizada en el programa de Radio Nacional No es un día cualquiera ${ }^{1}$, sobre el uso adecuado de esta expresión con el sentido de rechazo. Una oyente había criticado que un periodista de reconocido prestigio utilizara esa expresión para mostrar su desacuerdo con lo dicho por otro interlocutor. Algunas personas confiesan estar algo desconcertadas porque, en ocasiones, se les platean dudas sobre el uso de esta y otras expresiones y no saben dónde están los límites y qué significado comporta su uso.

Una de las posibles vías de solución podría ser el diccionario, por la rapidez con la que se puede acceder a algunos de ellos en internet y porque tiene la función principal de resolver dudas (Porto, 2002: 35). Sin embargo, este no siempre resuelve estas cuestiones, entre otros motivos, por el sentido vago o poco específico de algunas de las llamadas «marcas de uso» (coloquial, informal, etc.). Es probable que la falta de rigor y de sistematicidad en la información que aportan estas marcas se deba a lo difícil que resulta intentar solucionar este problema teniendo en cuenta, únicamente, la perspectiva gramatical y lexicográfica.

En los últimos años, la lexicografía funcional, representada, entre otros, por Sven Tarp y Fuentes-Olivera ${ }^{2}$, defiende que esta disciplina debe desarrollarse de acuerdo con las necesidades de los usuarios; es decir, debe conocer las dudas habituales a las que se enfrentan los hablantes para resolverlas de manera clara y eficaz.

Para nada manifiesta, ante todo, una actitud de disconformidad por parte del hablante con relación a un discurso previo; suele utilizarse en el plano coloquial de la lengua y ello obliga a introducir en el análisis otros elementos determinantes para su estudio como el registro (formal/coloquial), la actitud del hablante (cortés/(des)cortés), etc. Por este motivo, además del aspecto lexicográfico, hemos revisado algunos estudios pragmáticos sobre la negación y, más concretamente, sobre los actos disentivos.

Otro aspecto que se ha tenido en cuenta es la frontera que existe entre el registro oral y el registro escrito, ya que, aun cuando se reconoce ab initio, no siempre está clara. Como señala Briz (1998: 18), entre el discurso oral y el discurso escrito no existe una oposición tajante sino una presión continua. En este estudio nos hemos centrado en el discurso oral, aunque esta expresión también aparece en el plano de la lengua escrita, sobre todo en novelas, textos periodísticos, etc.

\footnotetext{
No es un día cualquiera es un programa que se emite en RNE los sábados y domingos por la mañana. En este caso, intervenimos durante la etapa anterior en la que conducía el programa la periodista Pepa Fernández.

2 Es interesante la teoría que esbozan Fuentes-Olivera y Tarp (2008) en el artículo «La teoría funcional de la lexicografía y sus consecuencias para los diccionarios de economía del español».
} 


\section{OBjetivos}

En este trabajo nos proponemos tres objetivos:

I) Revisar los dos usos de para nada, desde 1975, en que aparecen los primeros casos, hasta la fecha, y la evolución que ha tenido con valor de rechazo. Para ello nos hemos centrado en tres de los diccionarios más importantes del español: el Diccionario de la lengua española ${ }^{3}$ de la Real Academia Española, el Diccionario de uso del español ${ }^{4}$ de María Moliner y el Diccionario del español actual de Manuel Seco, Olimpia de Andrés y Gabino Ramos. Otros diccionarios, como el Diccionario CLAVE, el Diccionario Salamanca, el Diccionario General Ilustrado de la Lengua Española VOX, etc. nos han servido como punto de partida, pero nos hemos centrado en el análisis de los tres citados en primer lugar.

II) Comprobar la información que aportan las marcas de uso en estos diccionarios, en este caso, tanto en el registro oral como en el escrito: coloquial, culto, formal, informal, familiar, literario, popular, vulgar, etc.

III) Identificar los rasgos lingüísticos y pragmáticos (situaciones y condiciones de uso) que caracterizan la expresión para nada como operador enfático de negación en el nivel coloquial. Para ello hemos analizado 388 casos, correspondientes a tres períodos de diez años cada uno de ellos (1975-1985, 1992-2002 y 2006-2016), recogidos en el Corpus de Referencia del Español Actual y el Corpus del Español del siglo XXI de la Real Academia Española.

\section{MARCo teórico}

La expresión para nada requiere para su estudio un triple enfoque: gramatical, lexicográfico y pragmático. Los dos primeros son los que los diccionarios y gramáticas del español han cubierto en mayor o menor medida hasta ahora.

Como expresión negativa, para nada denota ante todo una actitud. En el capítulo de la Gramática descriptiva de la lengua española dedicado a la negación, Sánchez (1999: 2627) estudia pormenorizadamente todo lo relacionado con la ne-

\footnotetext{
En adelante, DRAE 1970, DRAE 1984, DRAE 1992, DRAE 2001 y DRAE 2014.

En adelante, DUE 1966-1967, DUE 1998, DUE 2007, y DUE 2016.

5 En adelante, $D E A 1999$ y $D E A 2011$.
} 
gación en términos gramaticales. Afirma que expresiones de este tipo tienen el valor de servir como refuerzo de la negación. Para nada pertenece, según esta autora, a las «palabras negativas» que tienen un significado de cuantificador indefinido. Se trata de respuestas negativas, modismos y frases hechas, más o menos lexicalizadas, que refuerzan la negación. En este estudio se recogen otras fórmulas provenientes de la clasificación de Beinhauer (1930), expresiones negativas de valor humorístico (¡nones!, ¡narices!), contradicciones enfáticas con la partícula ni (¡ni que estuviera yo loco...!), etc.

Cuando decimos que una expresión es adecuada o no se suele entender, en general, el uso con arreglo a las recomendaciones y directrices que marca la Academia, es decir, la norma académica. El concepto de 'norma' debe ser aclarado, ya que ha sufrido algunos cambios y caben varias interpretaciones. En este sentido, los cambios que se han producido en la Real Academia de la Lengua Española (RAE) están bien resumidos en palabras de Rizo (2019: 432), cuando dice:

La renovación que supuso la política panhispánica vino acompañada de la producción institucional de un discurso sobre la norma que se aparta del prescriptivismo que había sido atribuido históricamente a la Institución española. El resultado fue, en líneas generales, una atenuación del discurso normativo que se vio reflejada en los nuevos instrumentos lingüísticos de la era panhispánica...

Lo normativo hoy debe entenderse, al menos, en dos sentidos. El primero y más tradicional, de carácter prescriptivo y contrastivo, representado por la RAE, dicta el uso correcto que debe hacerse de la lengua; el segundo refleja el uso individual que hacemos de la lengua, menos impositivo. En este segundo sentido de norma $a^{6}$ es en el que se han producido numerosos cambios y es el que nos interesa. En líneas generales, queremos saber qué parámetros son los que deciden y condicionan que un uso considerado poco o nada académico, por no ajustarse a la norma, pueda ser considerado un uso aceptado; y si es aceptado, en qué contextos, registros, y, también, cuándo no se considera adecuado y por qué. La norma, el uso correcto o, incluso, el uso recomendable no es algo estático, como han demostrado numerosos estudiosos: está relacionado con factores como el nivel en el que se habla y las reacciones que provocan las expresiones utilizadas entre los interlocutores (rechazo, decepción, empatía, etc.).

6 Es interesante consultar Gómez Torrego (2013), dedicado íntegramente a la norma. Algunas de las propuestas de este artículo se encontraban ya esbozadas en una obra anterior del mismo autor (2011), en este caso, con un marcado carácter didáctico. 
Otro estudio interesante sobre el concepto de norma es el elaborado por Company (2013: 16-17) que entiende la norma en estos términos:

La norma es el uso convencional y establecido por siglos en una determinada comunidad lingüística, que, en consecuencia, constituye el uso más extendido en esa comunidad y que es no marcado en esa comunidad [...] La normatividad, como la estigmatización, es relativa y depende de variables sometidas a constantes transformaciones, tales como, el lugar donde se habla la lengua, la trayectoria histórica de la construcción, etc.

La norma, así pues, está sometida a constantes cambios y a situaciones y lugares en las que se produce el discurso.

Desde la perspectiva lexicográfica, la relación entre la norma y el diccionario ha sido estudiada por varios autores entre los que destacan Martínez y Garriga (2005: s/pp.), para los cuales el diccionario debe ser entendido como el «instrumento normativo por excelencia». Utilizan la expresión relativismo normativo para referirse al diccionario como una herramienta que nos facilita el uso de las palabras en su contexto, pero «no como una imposición de las posibilidades de expresión de una lengua». La norma y el uso son conceptos complementarios: «la norma regula el uso, es decir, establece los límites que el hablante debe conocer para expresarse dentro de esa idea de corrección ». Dentro de esa perspectiva lexicográfica, Fajardo (2011: 6667) ha analizado los problemas que conlleva la definición de una norma hispánica o, incluso, panhispánica, frente a los problemas de carácter nacional.

Por otra parte, Cundín (2001-2002: 45) reconoce que los diccionarios no suelen diferenciar el uso que puede hacerse de algunas expresiones en la lengua oral, que son impropias o poco recomendables en la lengua escrita. Esta reflexión nos sirve como punto de partida del análisis de la expresión para nada en los diccionarios del español actual.

Sobre esta expresión se han publicado en los últimos años algunos estudios, como el de Fuentes Rodríguez (2000: 82-84), en el que define para nada como un signo negativo de rechazo. La primera reflexión interesante que hace la autora es que no se puede identificar para nada con «en absoluto», ya que sus registros no coinciden (para nada, registro coloquial/en absoluto, registro formal). Para esta autora, para nada «exige un contexto interactivo de coloquialidad, en el que se marque no solo la negación, sino también el rechazo» (Fuentes Rodríguez, 2000: 83). Esto implica, a su vez, que esta forma no sea considerada adecuada en situaciones en las que cabe esperar cierta cortesía, como puede ser la diferencia de edad, la diferencia social, la falta de confianza, etc. El uso de para nada es, por tan- 
to, poco cortés, según el contexto. La segunda reflexión interesante es que «para nada es más que no», una negación rotunda, un rechazo absoluto. Por último, muy relevante para nuestro análisis ${ }^{7}$, afirma la autora que «el uso adecuado o no de un término lingüístico no solo depende de sus características gramaticales sino también, y en un elevado grado, de la relevancia en ese entorno comunicativo, y la adecuación a los interlocutores » (Fuentes Rodríguez, 2000: 84).

En la conversación coloquial son frecuentes y variadas las expresiones de rechazo y desacuerdo. Dentro del campo de la interacción, propio de este tipo de expresiones, Herrero (2002a: 126) define para nada como una forma propia de la conversación coloquial, concretamente, un operador que rechaza el valor ilocutivo del acto de habla previo. Poco después, Herrero (2002b: 224) concreta las características de los actos disentivos o actos asertivos negativos, que describe como segundas partes de un intercambio que expresan el desacuerdo con la primera parte del enunciado; suelen ser segundas partes no preferidas.

Por otra parte, Brenes (2015: 23-33) analiza el valor de para nada y otras formas que expresan rechazo, desacuerdo o disensión como un contenido modal, entendiendo la modalidad como la manifestación de la actitud del hablante a través de medios lingüísticos y gramaticales. Para nada, al igual que otras formas (de eso nada, ni hablar, ni pensarlo, etc.) se comporta, para esta autora, como un operador modal, es decir, como una unidad que forma un enunciado por sí mismo, sin ejercer ninguna función sintáctica en la oración. Concretamente, Brenes define esta expresión como un operador enfático de negación, un tipo de operador que admite el empleo autónomo como forma disentiva. Una de las conclusiones sobre la especialización de formas como para nada a las que llega es que pueden utilizarse con el adverbio no o sin él, como veremos más adelante con ejemplos tomados del corpus. Así, «esto hace que puedan aparecer a) integrados entonativamente como intensificadores de una negación previa y b) formando enunciados independientes e indicando desacuerdo y oposición...» (Brenes, 2015: 33).

Definido el valor de la expresión objeto de este trabajo, no es de extrañar que, en ocasiones, se alcen algunas voces que reclaman más rigor en la información que aparece en los diccionarios en este tipo de formas. Fuentes Rodríguez (2000: 83) no está de acuerdo con el $D R A E$, que, en su 22. a edición, identifica para nada con «en absoluto», y así sigue apareciendo en la última edición de 2014. Por su parte, Brenes (2015: 23) señala la inexactitud con que las acepciones de los operadores modales de rechazo se presentan en los repertorios lexicográficos.

Recordemos que la investigación surge a raíz de la duda que una oyente de radio le plantea a un conocido comunicador sobre el uso adecuado de para nada en un contexto en el que este respondía así a su interlocutor. 
La preocupación por mejorar tanto la clasificación como el valor de las marcas de uso no es nueva. Algunos estudios denuncian, desde hace años, la necesidad de reflejar en el diccionario la información sobre los registros de la lengua. Son interesantes, entre otros trabajos, el de Garriga (1994) sobre la marca vulgar y otro del mismo autor (1994-1995) sobre la marca despectivo en el DRAE. Fajardo (1996-1997: 34-43) constata en este sentido lo difícil que resulta homogeneizar el valor de las marcas de uso. La variedad que resulta de la comparación de marcas como familiar, popular, formal, informal, coloquial, etc., según hemos podido comprobar en el análisis contrastivo que, para este trabajo, hemos realizado entre los diferentes repertorios, se hace necesario revisar el valor de las marcas que orientan al hablante a utilizar con un determinado sentido las palabras y expresiones. Para Fajardo, una de las dificultades radica, y sigue siendo así, en «que las marcas del nivel de uso, de corrección y de estilo suelen implicarse mutuamente, de manera que lo vulgar se identifica con lo incorrecto, lo popular con lo informal o con lo coloquial, lo coloquial con lo familiar, etc.» (1996-1997: 34). La aparente arbitrariedad, junto con la polivalencia de algunas marcas, como la de coloquial, es una realidad todavía hoy, pese a los intentos por lograr la sistematización.

\section{Metodología}

Este apartado lo hemos dividido en dos puntos. En el primero (4.1) se explica cómo se han abordado los objetivos I y II. En el segundo, se expone el procedimiento llevado a cabo para desarrollar el objetivo III. Con la idea de que los datos se visualicen de forma clara hemos elaborado cinco tablas y dos gráficos que permiten valorar mejor los resultados.

\subsection{La expresión para nada en los diccionarios del español: las marcas de uso}

Para desarrollar el objetivo I hemos elaborado un análisis de los usos de para nada en los diccionarios seleccionados que nos permita dar cuenta de su evolución. Hemos tomado como referencia todas las ediciones del $D U E$ (cuatro) y del $D E A$ (dos); del diccionario de la Academia, hemos consultado desde 1970 hasta la última de 2014. Esta información queda recogida en la siguiente tabla: 
La expresión para nada y su evolución en el español oral. La información del uso en los diccionarios

\begin{tabular}{ccc}
\hline DRAE & DUE & DEA \\
\hline 1970 & $1966-1967$ & 1999 \\
1984 & 1998 & 2001 \\
1992 & 2007 & \\
2001 & 2016 & \\
2014 & & \\
\hline
\end{tabular}

Tabla 1. Diccionarios utilizados para el estudio de para nada

En un principio, para nada aparece en los diccionarios como sintagma preposicional con valor final. Como locución adverbial aparece por primera vez en el Diccionario de uso del español (1966-1967) de María Moliner con el valor de 'inútilmente', como en el ejemplo siguiente:

\section{(1) Te has molestado para nada.}

Dentro de la primera acepción, en este mismo diccionario aparece nada con el significado de 'pronombre equivalente a ninguna cosa o ninguna cantidad'. Esta primera edición nos remite, a través de la abreviatura $V(v e r)$, a la locución en absoluto, que es la primera referencia que se recoge en un diccionario del español con este valor. En la siguiente edición (DUE 1998) aparece por primera vez para nada con el significado que hoy se conoce, en una segunda acepción, con la marca informal:

Para nada. 1. 'Inútilmente'.

2. (inf.). Se utiliza con sentido negativo como equivalente a 'de ningún modo, 'en absoluto'.

Esta misma información es la que aparece en las dos ediciones siguientes ( $D U E$ 2007 y 2016). Un año después de la 2. a edición del DUE 1998, en el Diccionario del español actual, el DEA 1999 aparece este mismo sentido en la acepción 16. Se recoge como una subacepción, seguida de la marca coloquial, con el sentido de 'en absoluto'. DEA 2011 no cambia con respecto la edición anterior. Este diccionario cita los siguientes ejemplos:

(2) Diosdado, Anillos 1, 155: Lo entiendo perfectamente... - No entiendes para nada. 
(3) Pais 13.3.86, 10: podria pensarse que termina uno de los episodios más controvertidos y esquizoides de la nueva democracia española. Para nada es eso.

$(4)^{*}$ Ejemplo inventado del DEA: ¿Estás contento? - Para nada.

DRAE 1970 da como 6. acepción de la palabra nada, dentro de la categoría de adverbio de negación, el significado de 'en absoluto', 'de ningún modo'. En lo que se refiere a los diccionarios académicos, la locución adverbial para nada con valor coloquial no aparece hasta $D R A E 2001$, con el significado de 'de ninguna manera'. En la última edición, de 2014, no ha habido cambios.

Para desarrollar el objetivo II de este trabajo — revisar el significado que aportan las diversas marcas de uso que aparecen en los diccionarios- hemos elaborado tres tablas, una por cada repertorio, que ponen de manifiesto la falta de sistematicidad que existe en esta cuestión. Se demuestra, una vez más, que los diccionarios siguen cada uno su propio criterio sobre el sentido de dichas marcas; además de la arbitrariedad en la denominación y significados, la información que aparece es insuficiente porque solo se tienen en cuenta criterios gramaticales y semánticos, pero no, pragmáticos, muy necesarios para valorar el uso según la situación, los participantes, etc.

En la tabla 2, correspondiente al DUE, aparecen las cinco marcas referidas al plano de la lengua escrita y conversacional en este diccionario: tres para el plano formal de la lengua escrita (cult., form. y lit.) y dos para el plano informal (inf., fam.).

\begin{tabular}{|c|c|c|c|c|c|}
\hline & $\begin{array}{c}D U E \\
1966-1967\end{array}$ & $\begin{array}{l}D U E \\
1998\end{array}$ & $\begin{array}{l}D U E \\
2007\end{array}$ & $\begin{array}{l}D U E \\
2016\end{array}$ & Uso \\
\hline Culto (cult.) & sí & sí & sí & sí & $\begin{array}{l}\text { Voces propias del lenguaje elevado de } \\
\text { escritos o discursos, no adecuadas en la } \\
\text { conversación corriente }\end{array}$ \\
\hline $\begin{array}{l}\text { Familiar } \\
\text { (fam.) }\end{array}$ & sí & no & no & sí & Corriente, llano, sencillo \\
\hline $\begin{array}{l}\text { Formal } \\
\text { (form.) }\end{array}$ & sí & sí & sí & sí & $\begin{array}{l}\text { Menos elevado que el culto (textos expositi- } \\
\text { vos, administrativos) }\end{array}$ \\
\hline Informal (inf.) & sí & sí & sí & sí & $\begin{array}{l}\text { Propio, aunque no exclusivo, de la conversa- } \\
\text { ción entre personas de confianza }\end{array}$ \\
\hline Literato (lit.) & sí & sí & sí & sí & Voces exclusivas del lenguaje literario \\
\hline popular (pop.) & no & no & no & sí & $\begin{array}{l}\text { Uso propio de zonas rurales o clases popula- } \\
\text { res de las ciudades }\end{array}$ \\
\hline Vulgar (vulg.) & sí & sí & sí & sí & $\begin{array}{l}\text { Adecuadas en situaciones de mucha con- } \\
\text { fianza (sexo, insultos); también, expresiones } \\
\text { que denotan desprecio }\end{array}$ \\
\hline
\end{tabular}

Tabla 2. Marcas relacionadas con el uso (DUE) 
En el cuadro aparecen otras dos marcas que también se refieren al estilo, al registro o al nivel: popular (pop.) y vulgar (vg.). En la última casilla hemos resumido el uso que el $D U E$ asigna a cada una de estas marcas.

Los resultados obtenidos en este análisis confirman que las diferencias en el uso de algunas marcas (culto y formal, o culto y literario) no siempre están claras dentro de un mismo diccionario. Por ejemplo, la palabra deleitoso aparece con dos marcas culto o lit. (literario). La marca formal se define, únicamente, por una diferencia de grado o intensidad: formal «menos elevado que el culto $»$; la marca formal se utiliza, en este caso, en textos expositivos y administrativos.

La marca culto distingue en su descripción los dos planos, el de la lengua escrita formal y el de la lengua oral o plano conversacional: «voces propias del lenguaje elevado de escritos o discursos, no adecuadas en la conversación corriente $\gg . D U E$ utiliza la marca culto para designar «los usos propios del nivel escrito». La marca informal es la que se utiliza en las cuatro ediciones para referirse al uso de un vocablo «propio, aunque no exclusivo, de la conversación entre personas de confianza». Además de culto e informal, aparece la marca familiar (fam.) para referirse a las voces de uso «corriente, llano, sencillo». Esta marca aparece en la primera edición del año 1966-1967 y no vuelve a aparecer hasta la última de 2016.

Por su parte, la marca literario (lit.) se utiliza para « voces exclusivas del lenguaje literario», a diferencia de otros diccionarios, como el Diccionario del español actual $(D E A)$, que utiliza esta misma marca para «uso propio, en general, de las obras literarias o de la lengua escrita, o de situaciones formales; en especial, de la situación voluntariamente elegante o elevada $\gg$. Es decir, dos marcas distintas, literario en el $D E A$ y culto en el $D U E$ de María Moliner tienen el mismo valor.

En la tabla 3 recogemos los resultados obtenidos en el $D R A E$ sobre las marcas de uso como afectivo, despectivo, inusual, malsonante, peyorativo, popular, usado y poco usado; todas ellas están relacionadas con el uso, aunque aquí solo damos cuenta del valor de coloquial, culto, escrito y familiar. En el plano de la lengua formal, el $D R A E$ cuenta con dos marcas: culto (cult.) 'dotado de instrucciones que provienen de la cultura o de la instrucción' y escrito (escr.) 'propio de las ciencias y de la cultura'. Las dos aparecen por primera vez en la edición de 2001.

En este análisis hemos prestado especial atención a la marca coloquial, que es la marca con la que figura en los diccionarios la expresión para nada. Garriga (1997: 92) afirma que la marca coloquial aparece por primera vez en $D R A E 1984$. Por otra parte, en el análisis realizado sobre los diccionarios académicos hay dos marcas que se utilizan con un valor parecido: coloquial (coloq.) «propio de la conversación informal y distendida $\gg$ y familiar (fam.) «conversación normal y corriente». Como se observa en el cuadro, la marca familiar aparece en el diccionario académico en 
el año 70 (y en ediciones anteriores), mientras que la marca coloquial aparece por primera vez en $D R A E$ 1984, como hemos comentado. La descripción que se hace del uso de la marca coloquial coincide con el uso que le damos hoy a esa expresión.

\begin{tabular}{|c|c|c|c|c|c|c|}
\hline & $\begin{array}{c}D R A E \\
1970\end{array}$ & $\begin{array}{c}D R A E \\
1984\end{array}$ & $\begin{array}{c}D R A E \\
1992\end{array}$ & $\begin{array}{c}D R A E \\
2001\end{array}$ & $\begin{array}{c}D R A E \\
2014\end{array}$ & USO \\
\hline $\begin{array}{l}\text { Afectivo } \\
\text { (afect.) }\end{array}$ & no & no & no & sí & sí & \\
\hline $\begin{array}{l}\text { Coloquial } \\
\text { (coloq.) }\end{array}$ & no & sí & sí & sí & sí & $\begin{array}{l}\text { 2. Propio de una conversación } \\
\text { informal y distendida. }\end{array}$ \\
\hline Culto (cult.) & no & no & no & sí & sí & $\begin{array}{l}\text { Dotado de instrucciones que pro- } \\
\text { vienen de la cultura o instrucción. }\end{array}$ \\
\hline $\begin{array}{l}\text { Despectivo } \\
\text { (despec.) }\end{array}$ & sí & sí & sí & sí & sí & \\
\hline $\begin{array}{l}\text { Desusado } \\
\text { (des.) }\end{array}$ & sí & sí & sí & sí & sí & \\
\hline $\begin{array}{l}\text { Escrito } \\
\text { (escrit.) }\end{array}$ & no & no & no & sí & sí & $\begin{array}{l}\text { 3. Obra o composición científica } \\
\text { o literaria }\end{array}$ \\
\hline $\begin{array}{l}\text { Familiar } \\
\text { (fam.) }\end{array}$ & sí & sí & sí & sí & sí & $\begin{array}{l}\text { 4. Natural, sencillo y propio de la } \\
\text { conversación normal y corriente. }\end{array}$ \\
\hline $\begin{array}{l}\text { Inusual } \\
\text { (inus.) }\end{array}$ & sí & sí & sí & sí & sí & \\
\hline $\begin{array}{l}\text { Malsonante } \\
\text { (malson.) }\end{array}$ & no & no & no & sí & sí & \\
\hline $\begin{array}{l}\text { Peyorativo } \\
\text { (peyor.) }\end{array}$ & no & no & no & sí & sí & \\
\hline Popular (pop.) & sí & sí & sí & sí & sí & \\
\hline $\begin{array}{l}\text { Poco usado } \\
\text { (p.us.) }\end{array}$ & no & no & no & no & sí & \\
\hline $\begin{array}{l}\text { Usado (u.)/ } \\
\text { Usase }\end{array}$ & sí & sí & sí & sí & sí & \\
\hline Vulgar (vulg.) & sí & sí & sí & sí & sí & \\
\hline
\end{tabular}

Tabla 3. Marcas relacionadas con el uso (DRAE)

Sin embargo, la marca coloq. o col. sigue siendo, en DRAE 2014, una de esas marcas-polisémicas donde se agrupan, a veces, palabras que responden a usos diferentes porque se trata de niveles y situaciones muy distintas, entre las que cabe citar el lenguaje inclusivo, el machismo, la jerga juvenil, la conversación informal, etc. Estos son algunos ejemplos: 
(5) muslamen. m. coloq. 'Muslos de una persona, especialmente los de mujer'

(6) culín. m. coloq. 'Escasa porción que se sirve en un vaso'

(7) petar. intrs. coloq. 'agradar'

(8) tenienta: 2. coloq. p.us. 'mujer del teniente'

(9) en plan. m. coloq. 'Actitud o propósito'. Todo se llevó a cabo en plan amistoso.

(10) molar. intr. colq. 'Gustar, resultar agradable o estupendo'

Este mismo método hemos utilizado para el análisis del $D E A$, cuyos resultados aparecen en la tabla 4. En este caso hemos seleccionado tres marcas (coloquial, literario y semiculto). Este repertorio presenta una marca para el registro oral coloquial (col.); otra, para el registro formal o culto: literario (lit.), y la de semiculto (sem.) para los «usos de cierta difusión que, al menos por el momento, son rechazados como incorrectos o impropios por las personas cultas», pero que gozan de cierta difusión en la lengua escrita y hablada de personas de cultura superficial. Dentro de la falta de sistematicidad a la que aludíamos antes entre los diferentes diccionarios, la marca literario (lit.) en el DEA se corresponde con la marca (cult.) en DRAE 2014 y en $D U E$; la marca col. recoge en $D E A$ «aquellos usos que corresponden a una situación de confianza o familiaridad». La segunda edición del $D E A$ (2011) incorpora un Glosario de términos lingüisticos utilizados en el que se incluyen algunas de las marcas de uso, con una pequeña aclaración sobre su valor. Por ejemplo, coloquial. (col.): «Uso propio de la conversación informal o de una situación distendida».

\begin{tabular}{r|ccl} 
& DEA 1999 & DEA 2011 & Uso \\
\hline Coloquial (coloq.) & sí & sí & $\begin{array}{l}\text { Uso propio de la conversación informal o de una } \\
\text { situación distendida }\end{array}$ \\
\hline Despectivo (despec.) & sí & sí & \\
Eufemistico (euf.) & sí & sí & \\
\hline Jergal (jerg.) & sí & sí & \\
Juvenil (juv.) & sí & sí & Palabra o expresión propia de los jóvenes \\
Literato (lit.) & sí & sí & \\
\hline
\end{tabular}




\begin{tabular}{|c|c|c|c|}
\hline & $D E A 1999$ & $D E A 2011$ & Uso \\
\hline Peyorativo (peyor.) & sí & sí & Uso propio, de nivel cultural bajo \\
\hline Semiculto (sem.) & sí & sí & $\begin{array}{l}\text { Uso rechazado como incorrecto o impropio por } \\
\text { las personas cultas, pero que goza de cierta difu- } \\
\text { sión en la lengua escrita y hablada de personas de } \\
\text { cultura superficial }\end{array}$ \\
\hline Vulgar (vulg.) & sí & sí & $\begin{array}{l}\text { Palabra malsonante o de mal gusto que debe } \\
\text { evitarse en situaciones formales o ante personas } \\
\text { de cierto respeto }\end{array}$ \\
\hline
\end{tabular}

Tabla 4. Marcas relacionadas con el uso (DEA)

\subsection{La expresión para nada en los corpus del español}

Para desarrollar el objetivo III hemos consultado dos de las bases de datos de la RAE: el Corpus de Referencia del Español Actual ${ }^{8}$ y el Corpus del Español del siglo XXI ${ }^{9}$. En la selección de casos se han seguido los siguientes criterios. En primer lugar, y dado que teníamos que acotar el número de ejemplos, hemos escogido tres períodos de 10 años cada uno de ellos (1975-1985, 1992-2002 y 2006-2016), que coinciden con diferentes etapas de uso de la expresión para nada. En la búsqueda realizada, tanto en el CREA (1975-1985 y 1992-2002) como en el CORPES XXI (2006-2016), hemos seleccionado el medio oral porque nos ha parecido el medio más adecuado para encontrar casos de para nada pues, como se ha indicado, se atestigua en registro coloquial.

Con estos parámetros, son 388 los casos registrados en los que aparece para nada. La distribución de los casos puede verse en el gráfico 1. Hay que recordar que los documentos pueden ser de variada extensión (entrevista, novela, etc.), motivo por el cual ese parámetro, a veces, tampoco es muy fiable para saber la proporción en la que aparece la expresión por número de documentos.

8 El Corpus de Referencia del Español Actual (CREA), según la información que da la RAE en la página oficial, está formado por textos de diferente procedencia, producidos en todos los países de habla hispana entre 1975 y 2004, almacenados en soporte informático. Dado que solo vamos a utilizar los textos orales, de aquí en adelante lo denominaremos CREA Oral.

9 El Corpus del Español del Siglo XXI, según esta misma página, es un corpus formado por miles de textos y cientos de millones de formas; en junio de 2016 se presentó la una nueva versión 0.83 , que cuenta con más de 225 millones de formas. En adelante, CORPES XXI. 


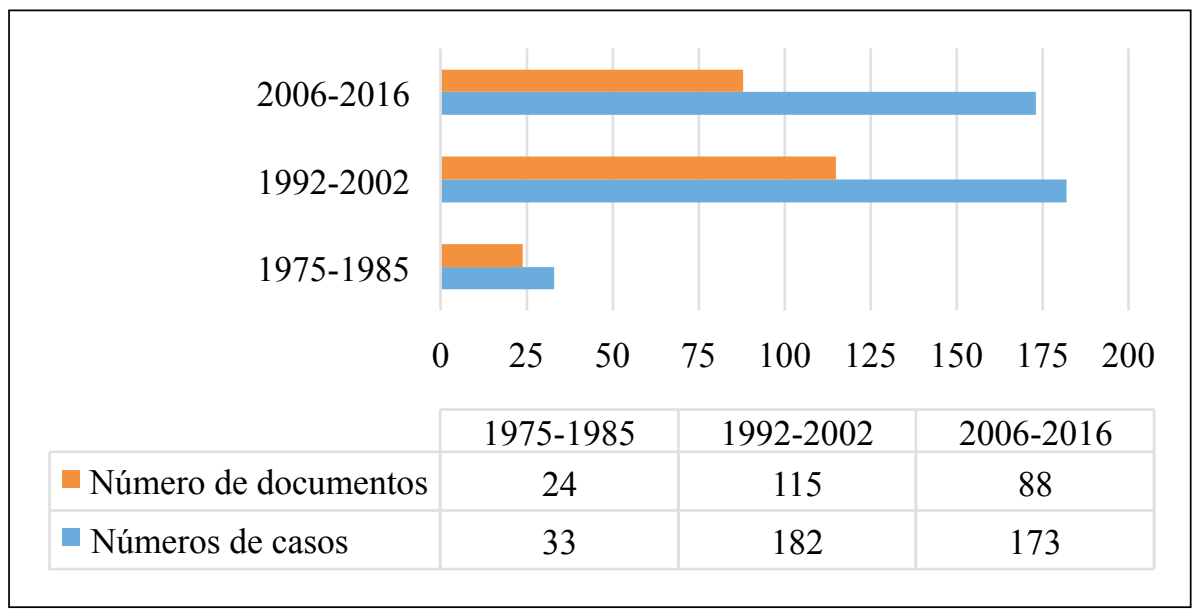

Gráfico 1. Relación de casos y documentos

El gráfico 2 da cuenta del valor porcentual y del número de casos del uso de para nada con valor de rechazo en el corpus oral de los tres períodos seleccionados en el CREA y en el CORPES XXI.

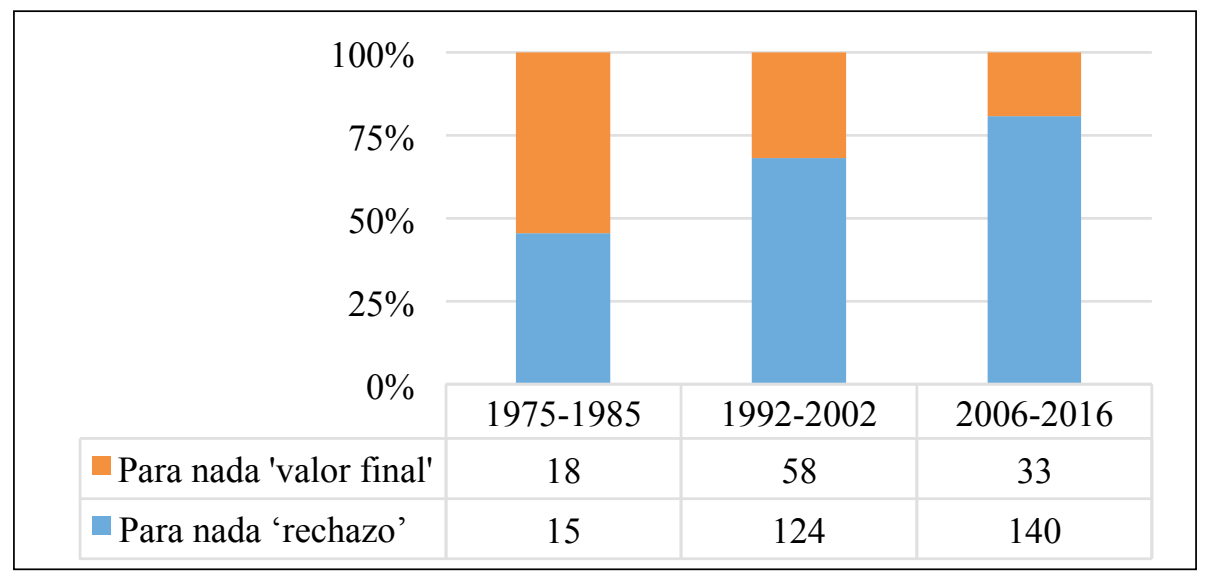

Gráfico 2. Análisis de para nada en el CREA Oral y en el CORPES XXI

De todos los casos registrados, hemos seleccionado para el análisis 30 ejemplos. Esta selección se ha realizado en función de dos criterios. Primero, que los ejemplos correspondan a los tres períodos analizados; segundo, que los ejemplos den cuenta 
de los dos significados más utilizados de para nada (el valor final y el sentido de rechazo), así como de su evolución. De estos treinta casos, veinte corresponden al valor de negación, frente a diez que tienen valor final, ya que, aunque en menor proporción, todavía se sigue utilizando.

Dado que en este tercer objetivo planteamos analizar la forma para nada como expresión de la disensión en contextos donde es imprescindible la coloquialidad, hemos elaborado una tabla con 17 de 30 casos analizados con el sentido de rechazo. La elección de estos 17 casos se debe a que casi todos ellos coinciden en la fuente con otros varios de los recopilados y son, por tanto, bastante representativos de las situaciones y condiciones de uso de esta forma, cuestión que desarrollaremos en el apartado del Análisis.

En esta tabla 5, el número del ejemplo que aparece a la izquierda corresponde al que ocupa en el apartado 5 del trabajo, donde se recogen los 30 casos. A continuación, señalamos el año, el medio, el programa o título y, por último, una breve caracterización que defina, de manera breve, la situación o el contexto en que se produce. Como se puede observar, los ejemplos 25 y 26 del Análisis proceden de novelas, es decir, de la lengua escrita, si bien es cierto que ambos reproducen diálogos entre dos personajes.

\begin{tabular}{|c|c|c|c|c|}
\hline Ejemplo & Año & Medio & Programa & Caracterización \\
\hline 14 & 1983 & TVE2 & $\begin{array}{l}\text { Si yo fuera } \\
\text { presidente }\end{array}$ & $\begin{array}{l}\text { Programa conocido por sus entrevistas com- } \\
\text { prometidas, originales, imaginativas } \\
\text { «Oralización de la prensa española». }\end{array}$ \\
\hline 16 & 1992 & TVE1 & Hola, Rafaella & $\begin{array}{c}\text { Programa muy popular de variedades en el } \\
\text { que los invitados charlaban de forma colo- } \\
\text { quial con la anfitriona. }\end{array}$ \\
\hline 21 & 1992 & TVE1 & $\begin{array}{c}\text { El show de la } \\
\text { una }\end{array}$ & $\begin{array}{l}\text { Programa emitido por las mañanas que } \\
\text { respondía al formato de magazine. }\end{array}$ \\
\hline 22 & 1996 & Tele 5 & $\begin{array}{l}\text { Esta noche } \\
\text { cruzamos el } \\
\text { Mississippi }\end{array}$ & $\begin{array}{c}\text { Programa conducido por Pepe Navarro con } \\
\text { entrevistas, a veces, polémicas. }\end{array}$ \\
\hline 23 & 1996 & $\begin{array}{c}\text { Radio } \\
\text { Cadena SER }\end{array}$ & $\begin{array}{c}\text { Hora } \\
\text { veinticinco }\end{array}$ & $\begin{array}{c}\text { Programa informativo nocturno sobre cues- } \\
\text { tiones de la actualidad. }\end{array}$ \\
\hline 25 & 2000 & Novela & $\begin{array}{l}\text { El alquimista } \\
\text { impaciente de } \\
\text { Lorenzo Silva }\end{array}$ & $\begin{array}{c}\text { Conversación en un registro coloquial entre } \\
\text { dos personajes. }\end{array}$ \\
\hline 26 & 2002 & Novela & $\begin{array}{c}\text { La mujer de mi } \\
\text { bermano } \\
\text { Jaime Bayly }\end{array}$ & $\begin{array}{l}\text { Conversación que describe en forma de } \\
\text { pregunta retórica el enfado del receptor. }\end{array}$ \\
\hline
\end{tabular}


La expresión para nada y su evolución en el español oral. La información del uso en los diccionarios

\begin{tabular}{|c|c|c|c|c|}
\hline Ejemplo & Año & Medio & Programa & Caracterización \\
\hline 30 & 2007 & $\begin{array}{l}\text { Encuesta-en- } \\
\text { trevista }\end{array}$ & $\begin{array}{l}\text { SCOM_ } \\
\text { M33_004 }\end{array}$ & $\begin{array}{l}\text { Respuesta de una enfermera de } 35-40 \text { años } \\
\text { en un tono coloquial. }\end{array}$ \\
\hline 31 & 2007 & $\begin{array}{l}\text { Encuesta-en- } \\
\text { trevista }\end{array}$ & $\begin{array}{l}\mathrm{SCOM}_{-} \\
\mathrm{H} 33 \_002\end{array}$ & $\begin{array}{l}\text { Respuesta de una estudiante de 15-19 años } \\
\text { con un lenguaje coloquial y espontáneo. }\end{array}$ \\
\hline 35 & 2012 & $\begin{array}{c}\text { Radio } \\
\text { Cadena SER }\end{array}$ & La ventana & $\begin{array}{l}\text { Entrevista realizada en un registro coloquial } \\
\text { a Daniela Sánchez (la prostituta del escánda- } \\
\text { lo de los agentes de Obama en Colombia). }\end{array}$ \\
\hline 36 & 2012 & Internet & $\begin{array}{l}\text { Eurovisión- } \\
\text { spain.com }\end{array}$ & $\begin{array}{l}\text { Entrevista a Pastora Soler antes de eurovi- } \\
\text { sión. Lenguaje espontáneo y coloquial. }\end{array}$ \\
\hline 37 & 2013 & TV México & $\begin{array}{c}\text { Tragaluz } \\
\text { Héctor Suárez }\end{array}$ & Entrevistas cortas, directas, «sin tapujos». \\
\hline 38 & 2014 & $\begin{array}{c}\mathrm{TV} \\
\text { Antena3 }\end{array}$ & $\begin{array}{c}\text { El Hormiguero } \\
3.0 \\
\text { Pablo Motos }\end{array}$ & $\begin{array}{l}\text { Entrevistas y entretenimiento; tono desenfa- } \\
\text { dado y registro coloquial. }\end{array}$ \\
\hline 39 & 2015 & $\begin{array}{l}\text { La Sexta } \\
\text { televisión }\end{array}$ & $\begin{array}{l}\text { Entrevista } \\
\text { Jordi Évole }\end{array}$ & $\begin{array}{l}\text { Formato entrevista-debate entre Albert } \\
\text { Rivera y Pablo Iglesias. }\end{array}$ \\
\hline 40 & 2015 & TVE1 & El debate & $\begin{array}{l}\text { Lenguaje formal que intenta llegar a la gente } \\
\text { con rasgos de coloquialismo. }\end{array}$ \\
\hline
\end{tabular}

Tabla 5. Fuentes representativas de contextos en que se enmarcan los ejemplos seleccionados

\section{ANÁlisis}

A continuación, realizaremos el análisis pormenorizado de los casos de la expresión para nada que hemos recopilado de los corpus. Algunos ejemplos de los 30 analizados en este apartado aparecen sin fecha, ya que así es como se recogen en el corpus. Por otra parte, en los casos en que para nada tiene valor final, la referencia aparece al final del ejemplo entre paréntesis. En los casos en que para nada tiene valor de negación, el ejemplo va precedido de una breve interpretación de la situación y del contexto entre corchetes, seguidos de la fuente.

En el período de 1975 a 1985, para nada aparece en 18 de los 33 casos registrados como un sintagma preposicional con sentido final, es decir, este uso es ligeramente superior al valor de la negación; en este caso, suele combinarse con verbos como servir, venir, contar, usar, haber, necesitar, etc. Estos son algunos de los ejemplos recogidos en el CREA Oral ${ }^{10}$ con este valor:

10 Los ejemplos que hemos seleccionado en los corpus de la Academia presentan a veces errores de redacción que no hemos corregido. Esto se debe, casi con seguridad, a que son textos transcritos de la lengua oral. 
(11) Eso se lo decía el papá y sin embargo el muchacho estudió, estudió, y después hizo lo del papá, no lo usó para nada, porque tenía mucho dinero... (Muestra XXVI, encuesta 3H/3M-207-d. Informante A: hombre, 62 años, Venezuela).

(12) Que se investigue algo para curarnos, porque nos quedamos tiesos de calambres y dolores, y el dinero no nos sirve para nada si no hay salud... (Informe Semanal, 12/06/82, TVE, España).

(13) Yo estudiaba inglés, pero sin pensar que me serviría para nada, simplemente por afición cultural o por interés. (SE-14. Mujer de 60. Profesora de instituto, España).

En este mismo período hemos encontrado 15 casos en los que para nada tiene el significado de rechazo. En los siguientes ejemplos (14 y 15), la expresión para nada se emplea dentro de un contexto interactivo, en el que se busca, intencionadamente, generar cierta confianza, como muestran los temas sobre los que versa la entrevista. Esta proximidad hace que su uso no resulte inadecuado o poco cortés:

(14) [En Si yo fuera presidente, Fernando García Tola pregunta a la entrevistada en tono incisivo y provocador, $25 / 10 / 83$, TVE 2].

¿Tú querrías ligar con Felipe González? No, para nada. Se lo dejo para Carmen que ya están bien. ¿Con quién querrías ligar tú de los políticos? ¿De los políticos? Sí. Con nadie, porque así el único que dice la gente que está bien es el Verstrynge, y a mí me parece un poco enjuto, y no me gusta. ¿No te gusta Verstrynge? No, para nada...

(15) [En la misma entrevista, el periodista tras haberle preguntado a la invitada si tiene novio o no, se interesa ahora por el valor que tiene para ella el trabajo, Si yo fuera presidente, 01/11/83, TVE 2].

Porque tú crees que el trabajo no libera. No, para nada. Bueno, a mí personalmente, no.

En ocasiones, lo que se busca es poner de manifiesto, de manera rotunda, el desacuerdo con lo dicho anteriormente, como en el ejemplo siguiente:

(16) [En el programa Hola, Raffaella, Raffaela Carrá trata de acercarse a sus oyentes con frases amigas y desmentidos, como en este caso, 05/08/92, TVE1]. 
Se ha corrido mucha tinta en esta historia y para nada, si nos estás escuchando, Isabel, nosotros...

En los 182 casos registrados en el CREA Oral en el período 1992-2002 se registran 124 casos con valor de rechazo frente a 57 en los que aparece el valor final. Se da, pues, un aumento importante del uso de para nada como operador enfático de negación.

Entre los 57 ejemplos de este segundo período en los que aparece para nada con valor final es también habitual la combinación con verbos como valer, servir, etc. Estos son algunos casos:

(17) Entonces se van a acortar, se van a quitar algunos contratos, que además no sirven para nada. (Tertulia de Hora 25, 13/03/97. Cadena SER, España).

(18) Después, ¿ para qué te vale? Es que no te vale, en la práctica no te vale para nada, ¿entiendes? (Entrevista CSC003, hombre, 22 años, España).

Este uso se ve reforzado a veces por el cuantificador más, como en los siguientes ejemplos:

(19) Y la concentración es absoluta, no hay tiempo para nada más (Al filo de lo imposible, quinta etapa, Atlántica, 15/04/95, TVE2).

(20) Claro, lo ofrezco para hacer una película, por ejemplo, estar interpretando, pero no lo ofrezco para nada más (Esta noche cruzamos el Mississippi, 06/11/96, Tele5).

Entre los 124 casos registrados con el valor de rechazo, encontramos algunos ejemplos en los que la negación se ve reforzada por la doble presencia de los adverbios muy y no, en construcciones poco habituales, como es muy no para nada, donde se produce una adjetivación:

(21) [En El show de la una, el periodista describe con énfasis a uno de sus invitados, 19/10/92, TVE 1].

Un hombre muy seguro de sí, muy ordenado, organizado. Lo tiene clarísimo, es muy no para nada. 
Con cierta frecuencia, la presencia del adverbio no intensifica el sentido negativo de para nada:

(22) [El periodista Pepe Navarro, en tono socarrón, se dirige a su personaje entrevistado que contesta con rotundidad, en Esta noche cruzamos el Mississippi, 21/10/96, Tele 5].

¿Y de las señoritas solteras y enteras también tiene usted miedo? No, para nada. Estoy encantado.

En absoluto puede tener o no valor enfático; cuando aparece junto a para nada hay una clara intención de enfatizar la negación:

(23) [Dentro de un tono coloquial, como denota el uso del marcador bueno, recogemos esta respuesta en Hora veinticinco, 06/11/96, Cadena SER]. Pero bueno, a mí no me molestaba, para nada, en absoluto.

En este período se encuentran algunos casos en los que la forma para nada aparece junto a expresiones coloquiales del tipo vamos, tal y $o$ sea, en ocasiones juntas en el mismo período oracional; la frase, por otra parte, responde a una organización sintáctica improvisada, propia también de este nivel coloquial, como sucede en el siguiente ejemplo:

(24) [Se trata de la intervención de alguien no identificado en una conversación, en tono coloquial, sin fecha, Alcalá de Henares]. Bueno, aquí está, pon la otra mejilla, o sea para nada habla de eso.

En ocasiones aparece para nada como respuesta única, con una mayor fuerza argumentativa. Como señala Brenes (2015: 27), para nada como operador enfático de negación forma un enunciado por sí mismo que expresa la actitud de desacuerdo del que lo dice con relación a su interlocutor. Esto es lo que sucede en los dos ejemplos que siguen a continuación. En estos casos, la expresión requiere un contexto íntimo, familiar, no siempre amable, como sucede en el ejemplo de Bayly, cuya respuesta es algo desafiante para el interlocutor.

(25) [El personaje Zaldívar lanza una pregunta a Laura, en El alquimista impaciente de Lorenzo Silva, 2000].

¿Te importa que nos tuteemos, Laura? -atacó Zaldívar, intrépido. Para nada - concedió ella-. 
(26) [En la novela La mujer de mi hermano de Jaime Bayly, uno de los hermanos formula una pregunta incómoda al otro del cual sospecha, 2002, Perú]. ¿Estás molesto? - Para nada

Para analizar la presencia de para nada entre los años 2006 y 2016 hemos consultado el CORPES XXI. Los datos recopilados en este estudio confirman que, en este período, el valor de para nada con el sentido de rechazo se expande todavía más que en el período anterior, fundamentalmente en el marco de un registro coloquial, como ya hemos señalado. De los 173 casos registrados, 140 corresponden a este uso, es decir, un $80,92 \%$ del total. En los 33 casos restantes se mantiene el valor final, lo cual confirma que este uso, en menor medida, sigue utilizándose en la lengua actual. Estos son algunos ejemplos:

(27) Yo no utilizo el ordenador para nada que no me exija mi trabajo (SCOM_M23_018, 2008).

(28) Y quedó el patio ese ahí que tenemos pues para nada, para nada y para todo, ¿̇no? (SCOM_H21_039, 2009).

(29) Lo que no voy expuesta es a que te vayas de narices, que te rompas la cadera, que vayas al hospital para nada ¡eh! (SCOM_M31_045, 2010).

En los 140 casos en los que aparece para nada como operador de negación, es frecuente que aparezcan otras expresiones idiomáticas, exclusivas de la lengua oral coloquial. Además de o sea, que ya aparece en el período anterior, hemos registrado otras propias de la lengua oral informal como tia, ¡hala!, y tal, ¿eeh?, ¿eh? y ¿mm?, como en el siguiente ejemplo:

(30) [Entrevista realizada a una enfermera, edad 35-54, a la vuelta de un viaje, SCOM_M23_004,2007].

Yo no eché de menos ni la comida ¿eh? pero para nada...

Un buen número de casos analizados corresponden a entrevistas grabadas para realizar algún estudio a personas con edades comprendidas entre los 15 y los 65 años. El denominador común de los ejemplos en los que aparece para nada es la búsqueda de un espacio común por parte de la persona que realiza la entrevista, con el fin de que el clima en el que se desarrolle la encuesta sea lo más distendido posible. 
Estos son algunos ejemplos:

(31) [Entrevista a una joven de 15-19 años que vuelve de un viaje por Italia, SCOM_H33_002, 2007].

Que Venecia en comparación con lo demás, que para nada, que no les gustó y que olía muy mal.

(32) [Entrevista a una mujer de 20-34 años, sobre su vida religiosa, SCOM M13_008, 2007].

Me da igual, y yo no soy extremadamente religiosa para nada, ni me preocupa, eh, la verdad.

(33) [Una mujer de más de 55 años, de nivel cultural bajo, es entrevistada sobre la relación entre los jóvenes y sus padres].

Hoy los jóvenes no tienen respeto a los padres para nada, y aunque tengan respeto solo lo tienen a su modo, ¿sabes?

(34) [Joven entre 20-34 años, en paro, entrevistado para una encuesta, SCOM_H11_047,2010].

No hace falta ir por ahí con cara de perro para nada, tía

En otras ocasiones, los ejemplos de entrevistas corresponden a otros contextos diferentes (radio, televisión, internet), pero con un denominador común: se tratan temas relacionados con la experiencia personal, a veces, temas nada cómodos para la entrevistada, como este del ejemplo 35:

(35) [Daniela Suárez, la prostituta del escándalo de los agentes de Obama en Colombia es entrevistada en «La Ventana », cadena SER, 2012].

No, para nada, no, no me han tratado de localizar...

(36) [Entrevista a Pastora Soler horas antes de la final de Eurovisión, en el programa eurovisión-spain.com, 2012].

Aunque la gente que no esté dentro de Eurovisión se empeñe en decir que ya es algo obsoleto, para nada, ¿no? Yo creo que incluso cada año se va haciendo más fuerte...

(37) [Héctor Suárez es entrevistado en el Tragaluz, acerca del libro que había publicado, México,2013].

¿Y no miente en su libro? Para nada. 
El valor de para nada como rechazo puede ser empleado, en ocasiones, con la intención del que habla de expresarse en un registro próximo a su interlocutor por edad, situación, etc., y, también, para captar receptores de ese mismo nivel, como sucede en los ejemplos 38 y 39; en ambos casos se busca generar un ambiente informal:

(38) [En tecnoxplora, el hacker Chema Alonso piratea el móvil de Pablo Motos, el Hormiguero 3.0, 2014].

El mail por defecto no viene cifrado para nada en un texto plano.

(39) [Jordi Évole, organiza un «cara a cara entre Albert Rivera y Pablo Iglesias en el bar del tío Cuco, en Barcelona, en un contexto informal. La Sexta Televisión, 2015].

Hay temas en los que ellos no están para nada de acuerdo, es decir, no tienen nada que ver...

Por último, este ejemplo es una muestra de cómo, a veces, el valor de para nada puede tener los dos sentidos, el de rechazo y el valor final, y da lugar a dos posibles interpretaciones. Este no es un caso aislado ya que aparece en otros analizados.

(40) [El comentario corresponde al debate celebrado entre Mariano Rajoy y Pedro Sánchez en diciembre de 2015. García Fernández, Emilio. El debate. TVE, 2015].

En uno de los gráficos que han aparecido en este último bloque no se mencionó para nada el dinero que se dedica a promoción.

\section{Conclusiones}

La expresión para nada, que en un principio se utilizaba únicamente con valor final, ha ido evolucionando hasta convertirse en una forma que expresa el desacuerdo o la actitud reactiva del interlocutor. Los 388 casos analizados permiten constatar que entre 2006 y 2016 el aumento del uso de para nada con valor de rechazo es casi el doble $(80,92 \%)$ con relación al que se hacía con este valor en el período inicial de $1975-1985$ (45,45\%).

La revisión de las marcas de uso en los tres diccionarios del español analizados y la forma en que aparece descrito el significado de la expresión para nada en estos repertorios nos ha llevado a varias reflexiones. En primer lugar, más que del significado, quizás deberíamos hablar del uso, porque la información que aportan esas acepciones son explicaciones relativas al valor gramatical y semántico, pero no son 
significados propiamente dichos: no tienen un contenido denotativo en el diccionario. En segundo lugar, en las últimas ediciones aparece recogido el uso negativo de para nada, pero sin ninguna información que permita atisbar qué otras interpretaciones cabe hacer del uso de la expresión, más allá del valor negativo, y en qué registros y con qué valor se puede utilizar. En tercer lugar, hemos confirmado que la mayoría de los ejemplos analizados aparecen en el nivel coloquial de la lengua, en el que para nada manifiesta, sobre todo, una actitud y, en concreto, una actitud de rechazo que va más allá de la negación, algo así como un no rotundo.

Por otra parte, el uso adecuado o no de una expresión implica la existencia de una norma que regula el uso que hacemos de la lengua. La norma, generalmente, la asociamos al denominado uso correcto que dicta la Academia. Pero cabe otra posibilidad, según la cual, el uso correcto puede estar relacionado con factores psicológicos y sociales, como el miedo a quedar mal, a ser criticado, etc. Son varias las razones que dificultan, a veces, que los hablantes sepan si resulta adecuado o no utilizar esta expresión. Esta y otras formas (para nada, ni lo pienses, ni hablar...) deben ser analizadas como expresiones que denotan actitudes. Por tanto, sería conveniente contar con el enfoque pragmático, más allá de la gramática y de la semántica, para homogeneizar y dar sentido a las denominadas «marcas de uso» en los diccionarios.

En conclusión, para que su uso resulte adecuado, la expresión para nada con valor de rechazo debe aparecer en el nivel coloquial y dentro de unos parámetros de confianza y de interacción entre los hablantes, ya que, de no ser así, el uso puede resultar descortés. De ahí que el uso adecuado dependa, en este caso, de factores pragmáticos.

\section{BibLIOgR A Fía}

BRENES, Ester (2015): «Aproximación pragmalingüística a las unidades modales empleadas en la expresión de la disensión y la descalificación», RILCE, 31.1, pp. 22-51.

BRIZ, Antonio (1998): El español coloquial. Situación y uso, Madrid, Arco/Libros.

Company, Concepción (2013): «La inevitable relatividad de la norma gramatical. Cambio lingüístico y valoración social», Español actual, 100, Madrid, Arco/ Libros, pp. 11-37.

Cundín, Margarita (2001-2002): «La norma lingüística del español y los conceptos coloquial y vulgar en los diccionarios de uso», Revista de Lexicografia, 8, pp. 43-102.

DEA 1999 = Seco, Manuel, Olimpia Andrés y Gabino Ramos (1999): Diccionario del español actual, $2 .^{a}$ edición actualizada, Madrid, Aguilar Lexicografía, 2 vols. 
DEA 2011 = Seco, Manuel, Olimpia Andrés y Gabino Ramos (2011): Diccionario del español actual, 2. ${ }^{\text {a }}$ edición actualizada, Madrid, Aguilar Lexicografía, 2 vols.

DRAE 1843 = Real Academia Española (1843): Diccionario de la lengua castellana, 9. ${ }^{a}$ ed., 1843, Madrid, Espasa Calpe.

DRAE 1970 = Real Academia Española (1970): Diccionario de la lengua española, 19. ${ }^{a}$ ed., Madrid, Espasa-Calpe.

DRAE 1984 = Real Academia Española (1984): Diccionario de la lengua española, 20. ${ }^{\text {a }}$ ed., Madrid: Espasa-Calpe.

DRAE 1992 = REAL ACADEMIA Española (1992): Diccionario de la lengua española, 21. ${ }^{a}$ ed., Madrid, Espasa Calpe.

DRAE 2001 = REAL ACADEMIA Española (2001): Diccionario de la lengua española, 22. ${ }^{\text {a }}$ d., Madrid, Espasa.

DRAE 2014 = Real Academia Española (2014): Diccionario de la lengua española, 23. ${ }^{\text {a }}$ ed., Madrid, Espasa Calpe.

DUE 1966-1967 = Moliner, María (1966-67): Diccionario de uso del español, Madrid, Gredos.

DUE 1998 = Moliner, María (1998): Diccionario de uso del español, 2. ${ }^{\text {ed., Ma- }}$ drid, Gredos.

DUE 2007 = Moliner, María (2007): Diccionario de uso del español, 3. a ed., Madrid, Gredos.

DUE 2016 = Moliner, María (2016): Diccionario de uso del español, 4. ${ }^{a}$ ed., Madrid, Gredos.

FAJARDo, Alejandro (1996-1997): «Las marcas lexicográficas: concepto y aplicación en la Lexicografía española », Revista de Lexicografía, 3, pp. 31-57.

FAJARDo, Alejandro (2011): «La norma lingüística del español desde una perspectiva lexicográfica: norma nacional versus norma hispánica », Normas. Revista de estudios lingüisticos hispánicos, 1, pp. 53-70.

Fuentes-Olivera, Pedro A. y Sven Tarp (2008): «La teoría funcional de la lexicografía y sus consecuencias para los diccionarios de economía del español», Revista de Lexicografia, 14, pp. 75-95.

Fuentes Rodríguez, Catalina (2000): «Para nada», Español Actual, 73, pp. 82-84. Garriga, Cecilio (1994): «La marca "vulgar” en el DRAE: de Autoridades a $1992 \gg$, Sintagma, 6, pp. 5-13.

Garriga, Cecilio (1994-1995): «Las marcas de uso: despectivo en el DRAE», Revista de Lexicografia, 1, pp. 113-147.

Garriga, Cecilio (1997): «Las marcas de uso en los diccionarios del español», Revista de Investigación Lingüistica, 1, pp. 75-110. 
Gómez Torrego, Leonardo (2011): Las normas académicas: últimos cambios, Madrid, SM.

Gómez Torrego, Leonardo (2013): «Comentarios a algunos cambios normativos recientes de la RAE», Español Actual, 100, pp. 59-85.

Herrero Moreno, Gema (2002a): «Formas y estructuras de desacuerdo en el español coloquial», Español Actual, 77-78, pp. 109-127.

Herrero Moreno, Gema (2002b): «Los actos disentivos», Verba, 29, pp. 221242.

Martínez Martí, Dolors y Cecilio Garriga (2005): «Norma y diccionario», Revista Textos, 39. En línea: < https://www.grao.com/es/producto/revista-textos-039-abril-05-la-normativa >.

Porto Da Pena, José-Álvaro (2002): Manual de técnica lexicográfica, Madrid, Arco/ Libros.

Rizzo, María Florencia (2019): «El discurso normativo de la RAE en Twitter», Revista de Investigación Lingüistica, 22, pp. 425-450.

SÁNCHEZ López, Cristina (1999): «La negación. Clases de estructuras negativas. Las palabras negativas», Gramática descriptiva de la lengua española, Madrid, Espasa-Calpe, vol. 2, pp. 2561-2634.

Fecha de recepción: 24 de abril de 2019 Fecha de aceptación: 23 de mayo de 2020 